\title{
Factors Influencing Provision Of Post Abortion Care Among Health Care Workers In Uasin Gishu County, Kenya
}

\author{
Wilson Kipkemboi Kemei \\ School of Public Health, Mount Kenya University \\ Email.wskkemei@gmail.com \\ Charles Walekhwa \\ School of Public Health, Moi University \\ Stanslaus Musyoki \\ School of Health Sciences, Kisii University. \\ DOI: 10.29322/IJSRP.11.09.2021.p11703 \\ http://dx.doi.org/10.29322/IJSRP.11.09.2021.p11703
}

\begin{abstract}
Ending unsafe abortion is a pressing public-health and human-rights imperative. In Kenya, unsafe abortion is among the five main reasons associated with maternal ill health and deaths and will remain so until safe abortion is more accessible across the country. In responding to unsafe abortion as a major but preventable reason for maternal deaths in Kenya, the Medical Services Ministry developed a Post-Abortion Care (PAC) policy to guide in forcing down unsafe abortion related ill-health and deaths in accordance with the 2010 constitution. It remains unclear how widely the PAC model is being implemented by health care providers who may be facing several challenges, consequently undermining prevention of maternal deaths. This study assessed factors that influence provision of post abortion care among health care workers in Uasin Gishu County. Specifically, the study established factors that influence provision of PAC among health care workers in relation to their knowledge, perception, practices and measures put in health facilities for provision of PAC. A Cross-sectional descriptive study was conducted in 18 health facilities providing reproductive health services in the County, targeting medical officers, Clinical officers and Nurses. Sample size was obtained using coefficient of variation formulae. Stratified and simple random sampling was applied. Data was collected using a structured schedule and analysed using SPSS. Pearson's correlation computed to test association between knowledge and practice of PAC among health workers was significant at $\mathrm{p}<0.001$. Spearman's correlation between Perception and measures in place for provision of PAC was also significant at $\mathrm{p}<0.001$. Binary logistic regression indicated that knowledge, practice and measures in place were significant predictors of provision of PAC, [Chi-Square $=5.868, \mathrm{df}=4$ and $\mathrm{p}=0.001(<0.05)]$. Perception was not significant. The study concluded that health providers had a knowledge gap on abortion law especially on the terms under which PAC can be executed lawfully. Lack of training on PAC and ill-equipped facilities was also established as a barrier to provision of PAC. The study recommended a pressing need to enlighten health providers on the subject of abortion legal framework and training on modern PAC practices so as to heighten their competence. The county government inevitably should ensure availability of essential commodities and supplies in readiness to scale up provision of PAC and prevent further maternal deaths.
\end{abstract}

Key words. Post abortion care, Health care worker, Uasin Gishu, Health facility. 


\subsection{Background to the Study}

Nearly half of all abortions (21.6 million) worldwide are unsafe, and nearly all unsafe abortions (98\%) occur in developing countries. Unsafe abortion therefore remains a reality for many women and will remain so until safe abortion is more accessible across the globe [1].

East Africa records the largest numbers of maternal mortality attributed to unsafe abortion globally where it is estimated that it accounts for one in every seven maternal deaths.

In Kenya, unsafe abortion is among the highest five main reasons associated with of maternal ill health and deaths [2].

Legally restricted abortion makes access to safe abortion difficult. Women in need of abortion services in such settings often resort to unsafe procedures leading to complications that require urgent medical intervention [1]. Consequently, most countries with rigid policies related to termination of pregnancy relaxed their abortion policies, hence, the concept of post abortion care (PAC) was adopted [3].

Apart from ethical issues, legal and technical setbacks related with provision of PAC also exist. Inadequately trained middle level care givers, lack of space, privacy, unsustainable access to instruments and shortage of other essential supplies has also been identified has a barrier to quality PAC in majority of health facilities within low-resource settings [4]. Barriers such as personal and religious beliefs that condemn abortion continue to limit access even where it is legally permitted [5].

Due to lack of PAC services in public hospitals, women have continued to obtain services in different settings including, private medical clinics, residences of traditional herbalists, places manned by untrained providers or even induce abortion themselves [6].

\subsection{Statement of the Problem}

The health risks of abortion depend on whether the procedure is performed safely or unsafely. In Kenya, Maternal mortality, to which unsafe abortion is a major contributor, continues to rise despite the constitution widening the provisions permitting access to safe services [7]. More concern is why health workers fail to prevent such deaths, yet, the law provides for safe options. The Ministry of Medical Services in Kenya came up with guidelines on provision of PAC in order to cut down illnesses and deaths related with unsafe termination of pregnancy in conformity with Kenyan fundamental law [8]. However, almost a decade later, PAC is rarely practiced in the public setting [6]. Little is known about knowledge, perception and practice of mid-level health providers towards provision of PAC in Kenya and also in Uasin Gishu County. For instance, to our understanding, there's no documented evidence on knowledge, perception and practice among care givers providing PAC services in approved health facilities within the County. Further, to our understanding, there is no documented report on health facility related factors that could influence implementation of PAC within the County. This study therefore aimed at assessing provision of PAC among care givers in health facilities within the County especially after the widening of indications for legal abortion in line with the 2010 constitution.

\subsection{Justification for the Study}

Maternal deaths resulting from unsafe abortion could best be reduced by preventing unintended pregnancies through contraception. The second-best measure is the provision of PAC. Lastly, management of complications of unsafe abortion can also help. All these measures are well stated in Reproductive Health Policy guidelines that, unintended pregnancy is prevented through family planning services; safe abortion services are to be provided where permitted by law and that abortion complications are to be managed by health care workers [8]. There is information that the first measure is being implemented, however, there is no information wether the second and the third measures are being provided by health workers in public institutions to the extent allowed by law. What could be the reason for this?

This could largely be related to the way the laws are being interpreted by health workers [9], their perception [10], or practice [11] towards PAC. Health facility level factors could also be lacking [12]. Little is known about these factors which could be undermining provision of PAC in the county.

\subsection{Research Objectives 1.4.1 Broad Objective}

To assess factors influencing provision of post abortion care among health care workers in Uasin Gishu County.

This publication is licensed under Creative Commons Attribution CC BY. 


\subsubsection{Specific Objectives}

1. To assess knowledge among health workers in Uasin Gishu County on provision of PAC.

2. To establish perception on provision of PAC among health workers in the County.

3. To identify the practice employed by health workers in the County, in provision of PAC.

4. To assess the measures put in health facilities for provision of PAC among health care workers in the County.

\subsection{Research Questions}

The researcher formulated the following questions to guide the study:

1. What knowledge do health workers in Uasin Gishu County have on provision of PAC?

2. How do health workers in Uasin Gishu County perceive provision of PAC?

3. How do health workers in Uasin Gishu County practice PAC?

4. Which measures have been put in health facilities for provision of PAC in the County?

1.6 Significance of the Study.

The findings of this study will be of benefit to the Ministry of health, policy makers in their efforts towards improved implementation of PAC. Findings will also benefit health system managers in their efforts towards preventing maternal mortality.

The study will as well be important to health related researchers and organizations that have an interest to contribute in fighting maternal deaths. Findings further provided baseline data on status of PAC implementation among care givers.

\section{LITERATURE REVIEW}

\subsection{Kenya Legislative Framework on Abortion}

The Kenyan legislative framework on termination of pregnancy and management of related complications is stated in the constitution and the Ministry of Health policy guidelines on reproductive health [8].

\subsubsection{Constitution of Kenya on Abortion}

Until 2010, abortion law in Kenya was highly restrictive, permitting abortion only to save the life of the woman. However, with the signing in of the new Constitution in the year 2010, indication for legal abortion was widened [13].

Article 26 (4) states that abortion can be permitted in the opinion of a trained health professional, when there is need for emergency treatment or the life or health of the mother is in danger. Under article 43 (1a), the Constitution further stipulates that every person has the right to the highest attainable standard of health, which includes the right to health care services, including reproductive health care [13].

\subsubsection{Ministry of Health Policy Guidelines on Reproductive Health.}

When a qualified health worker performs termination of pregnancy, the procedure is safe; further, all health professionals performing termination of pregnancy and or PAC services should be trained appropriately since competency based training enables providers to make decisions and have skills for providing services [8].

The policy further stipulates that treatment of abortion complications must be offered within health setups having appropriate equipment and only in those facilities that operate legally. The policy states that the client must be duly informed and referred where health setup cannot support the procedure. Health practitioners have a right to provide or not to provide service however; the liberty should not hinder access to PAC for those who need service. A qualified health practitioner, who feels unable to provide PAC services, should immediately refer the client who is eligible to a facility where she can obtain help. No qualified health worker should refuse to offer emergency service or post abortion treatment [8].

\subsection{Challenges Affecting Implementation of PAC}

There are individual, provider and health system level challenges that affect implementation of PAC services in Kenya [14]. These barriers trigger delays in seeking PAC, worsen complications and result in high levels of mortality [15].

\subsubsection{Knowledge among Service Providers on PAC Legal Framework}

Medical advancement that ensures abortion is safe is not any more a trouble, however the handiness of and availability of these advancements remains a tougher set back. Knowledge gap and cognizance on exact items authorized by law persists among service providers [9].

Access to pregnancy termination services in Kenya is still confined has an exclusive remedy necessary to bring to safety the life of the client [9]. Accessibility of PAC among women therefore largely hinge upon how service providers, courts and policy makers interpret the law. Laws that are unqualified by medical systems can be hard to interpret leading to unnecessary restrictions. If medical protocols do not provide guidance, health care providers can possibly decline to offer services to women in need, so as to avert the possibility of being punished for breaching the law [16].

\subsubsection{Perception of Health Care Providers on PAC}

Culture and religion has been a major determinant in abortion law landscape throughout the world and a force to reckon when implementing reproductive health policies. For instance, during the clamor for constitutional referendum, issues relating to abortion were listed as contentious by religious leaders. Abortion is still deemed unacceptable in many cultures and is against the teaching of almost all religions [17].

In a study conducted in Zambia, to assess the attitudes among health care workers in relation to provision of abortion services, findings identified that $88 \%$ of the respondents weighed termination of pregnancy as being immoral [18].

Due to lack of PAC services in public hospitals, Kenyan women have continued to obtain services in different settings including, private medical clinics, residences of traditional herbalists and in places manned by untrained providers [6].

\subsubsection{Practice of PAC among Health Providers}

This publication is licensed under Creative Commons Attribution CC BY. 
There is evidence that Manual Vacuum Aspiration and medication abortion is the procedure of choice commonly applied for the treatment of post-abortion complications. However, other unsafe methods like Dilatation and curettage continue to be widely provided in Kenya, suggesting critical inequities in availability of basic essentials for PAC and safe induced abortion across facilities and regions [2]. A South African study observed that training opportunities for PAC were sporadic due to lack of interest among providers. Stigma associated with PAC services also come up as a stabling block to accessing training, even when training was availed. Attending PAC related training signified a pro-abortion position, consequently exposing a service provider for blame [19]. Similarly, in Kenya, the deficit of health workers who can offer termination of pregnancy is more synergized by confinements set on qualified health care practitioners like, nurses, clinical officers and doctors, who hinder them from offering abortion services, thereby worsening the already existing provider deficit [20].

2.3.4 Measures in place for Provision of PAC

Availability and quality of necessary equipment and infrastructure has been identified has one of the barriers in provision of PAC [9]. Research findings from a 2013 study on access to PAC in Burkina Faso revealed how constraints related to equipment can exacerbate the financial cost of PAC in part by confronting women with informal payments hence denying them service [21]. Other major health system challenges to the provision of PAC services are non-availability of medical drugs used in PAC, in adequate basic supplies and commodities, old nonfunctional PAC equipment and lack of designated space for PAC within the health facility [15]. 


\subsection{Study Design}

\section{RESEARCH DESIGN AND METHODOLOGY}

The study adopted a descriptive cross-sectional research design utilizing a quantitative method, conducted in Uasin Gishu County. The cross sectional study allowed the researcher to compare many different variables at the same time and their correlation with the main variable. Since data is collected once, it minimized dropouts from the study. The unit of analysis was the individual participant.

\subsection{Study Variables}

The first independent variable was knowledge, to assess the knowledge of health care workers on provision of PAC. The second was perception, to establish the perception of health workers towards post abortion care. The third was practices, to identify the methods employed by health care workers in management of post abortion clients. The fourth independent variable was on health system to assess the measures in place for management of patients of post abortion in health facility within the County.

Just like other similar studies that seek to establish Knowledge, perception and practices [22], the first and third independent variables were evaluated using scores where responses to options that were true of PAC were considered as correct hence indicative of good knowledge or good practice, while responses that were not true of PAC were considered incorrect hence indicative of a gap in knowledge or deficiency in practice of PAC. The second and the fourth independent variables were evaluated using Likert scale scores on the level of respondents' feelings towards PAC or level of satisfaction on facility's preparedness to provide PAC.

\subsection{Study Area}

The study was done in Uasin Gishu County. The County consists of six Sub counties including: Kapseret, Kesses, Turbo, Soy, Ainabkoi and Moiben. The County population stood at 894,179 in 2009 with an annual growth rate of 3.5\%. [23].

\subsection{Study Population}

The study targeted all Medical Officers, Clinical Officers and Nursing Officers working at the 18 public health facilities that provide reproductive health services within Uasin Gishu County.

\subsubsection{Inclusion and Exclusion Criteria.}

All Medical Officers, Clinical Officers and Nursing Officers working at the 18 public health facilities that provide reproductive health services within Uasin Gishu County, who voluntarily consented in writing to participate in the study, were included.

Health workers who do not work in the 18 public health facilities were excluded. All other cadres of health workers other than nurses, Medical and Clinical Officers were excluded.

\subsection{Sampling and Sample Size Determination}

The public sector comprised of two County hospitals, 6 sub county hospitals, 17 health centers and 90 dispensaries. These public facilities were supported by one national referral hospital. Training of care givers on PAC was conducted by Ipas in some Public health facilities. A total of 18 health facilities provided reproductive health services in the County during the time of data collection. Purposive sampling was used to select the 18 public health facilities that provide reproductive health services in the County. A sampling frame was drawn comprising a list of all Medical Officers, Clinical Officers and Nurses working at the 18 facilities. The study purposively targeted these categories of care givers since the reproductive health framework allows them to provide PAC under certain specified circumstances [8]. Stratified sampling as per the 3 cadres was calculated, and then random sampling was used to pick those that were enrolled in each stratum. A coefficient of variation formula [24] was used to determine the sample size.

\subsection{Reliability and validity}

Research assistants were trained on research methods before commencing the study. The questionnaire was pretested so as to authenticate its validity and reliability. As suggested by [25], reliability of the questionnaire was checked using Coefficient of internal consistency where Alpha value between 0.626 and 0.871 was established for all the study objectives. Overall Cronbach's alpha was 0.725 . Content validity was ensured through appraisal of the supervisors and colleagues who were deemed to be experts in the study area.

\subsection{Data Management and Analysis}

Data was cleaned, coded and analyzed using SPSS version 20, where descriptive and inferential statistics was computed. Under descriptive analysis, percentages and measures of central tendency were utilized. Pearson's correlation was used to test the association between independent variables with continuous outcome data whereas spearman's correlation was used to test the association between independent variables with ordinal outcome data. Under inferential analysis, binary logistic regression was utilized to test hypotheses.

\subsection{Ethical Consideration}

Institutional Research and Ethics Committee (IREC) approved the study, while authorization was obtained from Mout Kenya University. All participants were informed about the study rationale, methodology and expected benefits. The study obtained written informed consent from all the participants. Confidentiality was guaranteed during data collection and analysis by limiting access of raw data to the researcher only.

\subsection{Response Rate of the Study.}

\section{RESEARCH FINDINGS AND DISCUSSION}

A total of 81 questionnaires were filled and returned. This study was composed of 20 question items and each question after analysis had $100 \%$ response rate. A response rate of $70 \%$ and above is considered excellent [26].

\subsection{Socio-demographic Characteristics of Participants.}


Table 4.1 shows the socio demographic characteristics of 81 study participants.

Table 4.1: Demographic Characteristics of Study Participants

\begin{tabular}{lcr}
\hline Variables & (n) & $(\%)$ \\
\hline i). Age & 1 & 1.2 \\
Below 25 years & 33 & 40.7 \\
26-35 years & 39 & 48.2 \\
36-45 years & 8 & 9.9 \\
Above 45 years & 16 & 19.8 \\
ii). Gender & 65 & 80.2 \\
Male & & 66.7 \\
Female & 54 & 8.6 \\
iii). Occupation. & 5 & 21 \\
Nurse (KRCHN) & 7 & 3.7 \\
Nurse (BSN) & 17 & 3 \\
Clinical Officers & 3 & \\
Medical Officers & & \\
\end{tabular}

\section{Key: $\mathrm{n}=$ frequency; $\%$ = percentage}

\subsection{Knowledge on PAC among Participants.}

Majority of the respondents $(81.5 \%)$ correctly identified that unsafe abortion is one among the 5 top most causal agent of death in women while $77.8 \%$ knew the WHO definition.

Regarding abortion legislative framework, $48.2 \%$ of participants knew that clinicians can perform abortion services to save life. Among the respondents, majority (45\%) were sure that PAC should be carried out only in equipped health facilities with an authorized skilled health worker, however, $33.3 \%$ of the respondents had no idea that healthcare practitioners had a duty not to object abortion related services during an emergency.

\subsection{Perception of Participants on PAC}

The research established the degree to which various statements describing health care worker's perception, influence provision of PAC services, using a 5 point likert scale. The statements describing perception of participants on PAC was graded in a sequence where $1=$ strongly disagree, $2=$ disagree, $3=$ undecided, $4=$ agree and $5=$ strongly agree. Study results were as shown in Table 4.4.

\section{Table 4.4: Perception of Participants on PAC.}

\section{No Statements}

a) I support pregnancy to be terminated in a woman with a pregnancy that endangers her life if she consents.

b) I support provision of PAC services to a woman with incomplete abortion of up to 12 weeks gestation.

c) Provision of PAC services is not contrary to my personal/religious beliefs.

d) I am personally committed to frequently update my understanding on the subject of $\mathrm{PAC}$ so as to provide services to deserving clients.

e) I support provision of PAC services to deserving clients as provided for under the constitution.
f) Abortion related policies and protocols are clearly developed to clarify its legality.

\subsection{Health Care Workers Practices Employed on PAC.}

\begin{tabular}{|c|c|c|c|c|}
\hline (n) & Q1 & Q3 & Median & IQR \\
\hline 81 & 3 & 4 & $4(74.1 \%)$ & 1 \\
\hline 81 & 2 & 4 & $4(62.9 \%)$ & 2 \\
\hline 81 & 1 & 2 & $2(69.1 \%)$ & 1 \\
\hline 81 & 2 & 3 & $2(72.8 \%)$ & 1 \\
\hline 81 & 2 & 3 & $2(61.7 \%)$ & 1 \\
\hline 81 & 2 & 2 & $2(60.5 \%)$ & 0 \\
\hline
\end{tabular}


ISSN 2250-3153

Regarding training for PAC, only 33.3\% had undergone training on PAC; however 37\% among the trained did not practiced. On recommended surgical method for terminating a pregnancy of up to 3 months, $49.4 \%$ correctly stated that WHO recommended MVA as the effective treatment for complications.

With regard to the choice of drugs recommended for medication abortion, half of the respondents correctly choose mifepristone and misoprostol, while another half generally did not know the recommended drugs. For those who were trained and were practicing abortion related services, $47.1 \%$ practiced combined medication abortion and manual vacuum aspiration whereas $29.4 \%$ practiced MVA only. Another $17.6 \%$ practiced medication abortion only.

On the state of health to which participants should permit PAC service to clients following complications of unsafe abortion, $50.6 \%$ wrongly thought a woman should be in a state of ill health in order to get service, while $37 \%$ correctly stated that the client must not necessarily be sick looking for PAC service to be provided.

4.5 Measures put in Health Facilities for provision of PAC.

A 5 point linkert scale was utilized and statements describing measures in place for management of patients of PAC in health facilities were arranged in a sequence ranging between $1=$ strongly disagree, $2=$ Disagree, $3=$ Undecided, $4=$ Agree and $5=$ strongly agree . The study results were as shown in table 4.10.

\section{Table 4.10: Available Equipment and Supplies for Provision of PAC.}

\begin{tabular}{|c|c|c|c|c|c|c|}
\hline No & Statements & (n) & Q1 & Q3 & Median & IQR \\
\hline 1) & $\begin{array}{l}\text { Adequate MVA Kits are available for } \\
\text { provision of PAC services in my facility }\end{array}$ & 81 & 1 & 2 & $2(61.7 \%)$ & 1 \\
\hline 2) & $\begin{array}{l}\text { Sterilization equipment is available in my } \\
\text { facility. }\end{array}$ & 81 & 1 & 2 & $2(65.4 \%)$ & 1 \\
\hline 3) & $\begin{array}{l}\text { Space designated for PAC services is } \\
\text { available in my facility. }\end{array}$ & 81 & 2 & 2 & $2(74 \%)$ & 0 \\
\hline 4) & $\begin{array}{l}\text { Guidelines on PAC are available in my } \\
\text { facility. }\end{array}$ & 81 & 2 & 2 & $2(75.3 \%)$ & 0 \\
\hline 5) & $\begin{array}{l}\text { Adequate Family planning commodities for } \\
\text { post Abortion clients are available in my } \\
\text { facility. }\end{array}$ & 81 & 1 & 3 & $2(48.1 \%)$ & 2 \\
\hline 6) & $\begin{array}{l}\text { Adequate medical supplies and commodities } \\
\text { for PAC are always available. }\end{array}$ & 81 & 1 & 2 & $1(50.6 \%)$ & 1 \\
\hline
\end{tabular}

\subsection{Research Analysis.}

\subsubsection{Descriptive Statistics}

Under descriptive analysis, percentages mean and standard deviation were utilized to describe data with continuous outcomes as shown in Table 4.11., whereas Pearson's correlation of coefficient was used to test the association between independent variables with continuous outcome data as shown in Table 4.12

Table 4.11 Mean and Standard Deviation for Continuous Outcome Variables

$\begin{array}{llllll}\text { Variables } & \text { N } & \text { Minimum } & \text { Maximum } & \text { Mean } & \text { Std. Deviation } \\ \text { Knowledge } & 81 & 5 & 25 & 16.67 & 4.809 \\ \text { Practices } & 81 & 5 & 25 & 14.26 & 5.869\end{array}$

Pearson's correlation between knowledge and practices on PAC was found to be statistically significant at $\mathrm{p}<0.001$. This implies that whenever knowledge improves, there is a likelihood of improvement on the practices among health care workers.

Table 4.12. Pearson's Product moment between Knowledge and Practice Correlations

\begin{tabular}{|ll|r|r|}
\hline & & KNOWLEDGE & PRACTICE \\
\hline \multirow{2}{*}{ KNOWLEDGE } & Pearson Correlation & 1 & .122 \\
& Sig. (2-tailed) & & .001 \\
& $\mathrm{~N}$ & 81 & 81 \\
& Pearson Correlation & .122 & 1 \\
PRACTICE & Sig. (2-tailed) & .001 & \\
& $\mathrm{~N}$ & 81 & 81 \\
\hline
\end{tabular}

Spearman's correlation was calculated to test the association between independent variables with ordinal outcome data. Spearmen's correlation between perception and measures in place on PAC among the respondents (Table 4.13) was found to be statistically significant at $P<0.001$. These findings imply that whenever the level of satisfaction among health care workers on measures in place improves, there is a likelihood of improvement on perception of PAC. 
Table 4.13. Spearman's Correlation between Knowledge and Practice

\section{Correlations}

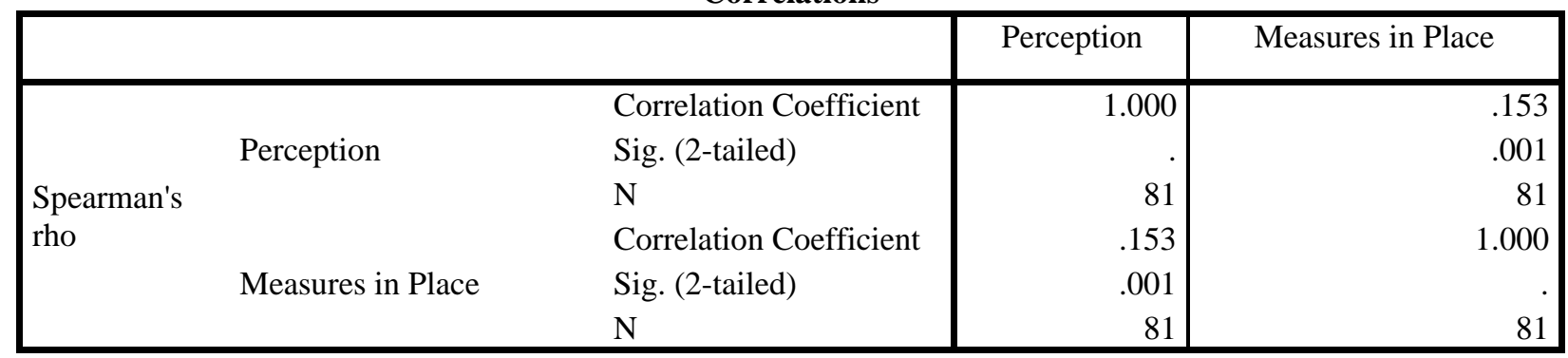

\subsubsection{Inferential Statistics}

\subsubsection{Binary Logistic Model}

Binary logistic regression was performed to ascertain the influence of independent variables on the likelihood that participants provide PAC.

Under this type of model, the probability of an event occurring is estimated. The model can be written as:

$$
\operatorname{Prob}(\text { event })=\frac{1}{1+e^{-z}}
$$

For many independent variables, the model is:

$$
z=b_{0}+b_{1} x_{1}+b_{2} x_{2}+\cdots \cdot b_{n} x_{n}
$$

where $b_{0}$ and $b_{1}, b_{2}$, are coefficients estimated from the data, $x_{1}, x_{2}$, are the independent variables, $n$ is the number of independent variables, $\mathrm{Z}$ is the dependent variable and $\mathrm{e}$ is the base of natural logarithms (2.781).

The variables that were used in the model are:

1. Knowledge - Knowledge on PAC among the respondents $(0=$ High score, $1=$ Poor $)$.

2. Perception - Perception on PAC among the respondents $(0=$ Good, $1=$ Poor $)$.

3. Practice - Practice of PAC among the respondents $(0=$ Good score, $1=$ Poor score $)$.

4. Measures put in Place for providing PAC $(0=$ Good, $1=$ Poor $)$

5. PAC - Provision of PAC ( $0=$ Provide, $1=$ Not provide $)$.

In the classification table, the constant only model predicted provision of PAC for "not provide" $100 \%$. The overall correct percentage prediction rate is $74.1 \%$.

\begin{tabular}{|c|c|c|c|c|}
\hline & \multirow{3}{*}{ OBSERVED } & \multicolumn{3}{|c|}{ PREDICTED } \\
\hline & & \multicolumn{2}{|c|}{ PAC } & \multirow{2}{*}{$\begin{array}{c}\text { PERCENTAGE } \\
\text { CORRECT }\end{array}$} \\
\hline & & NOT PROVIDE & PROVIDE & \\
\hline Step 0 & $\begin{array}{ll}\text { PAC } & \text { NOT PROVIDE } \\
& \text { PROVIDE } \\
\text { OVERALL PERCENTAGE }\end{array}$ & $\begin{array}{l}60 \\
21\end{array}$ & $\begin{array}{l}0 \\
0\end{array}$ & $\begin{array}{c}100.0 \\
.0 \\
74.1\end{array}$ \\
\hline
\end{tabular}

Table 4.14. Classification Table ${ }^{a, b}$

a. Constant is included in the model.

b. The cut value is .500

The Omnibus Tests for the Model Coefficients which compares the constant only model to the model with all the independent variables, showed $[\mathrm{Chi}=5.868, \mathrm{df}=4$ and $\mathrm{p}=0.002(<0.005)$

Table 4.15 Omnibus Tests of Model Coefficients

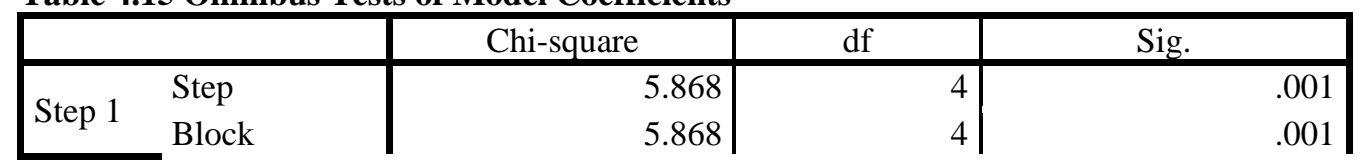

This publication is licensed under Creative Commons Attribution CC BY. 
In the Model Summary table, information about the goodness of fit of the model is provided. Nagelkerke R Square it is clear that $50.3 \%$ of the variation in Provision of PAC is account for by Knowledge, Perception, Practice and Measures put in place.

Table 4.16 Model Summary

\begin{tabular}{|l|l|l|l|}
\hline \multicolumn{1}{|c|}{ Step } & \multicolumn{1}{|c|}{-2 Log likelihood } & \multicolumn{1}{|c|}{ Cox \& Snell R Square } & \multicolumn{1}{c|}{ Nagelkerke R Square } \\
\hline 1 & $86.841^{\mathrm{a}}$ & .070 & .503 \\
\hline
\end{tabular}

a. Estimation terminated at iteration number 5 because parameter estimates changed by less than .001 .

The Classification Table compares the model predictions to the actual observation. The model predicted respondents who do not provide PAC compared to those who provide as $84.8 \%$ versus $65.0 \%$. Overall $77.4 \%$ of the 81 respondents were correctly classified. Table 4.17 Classification Table ${ }^{\mathrm{a}}$

\begin{tabular}{|c|c|c|c|c|}
\hline & \multirow[t]{3}{*}{ Observed } & \multicolumn{3}{|c|}{ Predicted } \\
\hline & & \multicolumn{2}{|c|}{ PAC } & Percentage Correct \\
\hline & & NOT PROVIDE & PROVIDE & \\
\hline Step 1 & $\begin{array}{ll}\text { PAC } & \text { NOT PROVIDE } \\
& \text { PROVIDE } \\
\text { Overall Percentage }\end{array}$ & $\begin{array}{l}59 \\
20\end{array}$ & $\begin{array}{l}1 \\
1\end{array}$ & $\begin{array}{l}98.3 \\
4.8 \\
74.1\end{array}$ \\
\hline
\end{tabular}

a. The cut value is .500

The Variable in the Equation Table shows the estimated coefficients for Knowledge, Perception, Practice, Measures put in place and the constant under the column heading B. The odds ratio (OR) is given in the column Exp (B) with the 95\% Confidence Interval of Exp (B) also given in the last column of the table.

Table 4.18 Variables in the Equation

\begin{tabular}{|cl|l|l|l|l|l|l|}
\hline \multicolumn{2}{|c|}{} & B & S.E. & Wald & df & Sig. & $\operatorname{Exp(B)}$ \\
\hline \multirow{2}{*}{ Step 1 ${ }^{\mathrm{a}}$} & Knowledge & -.056 & .059 & 1.710 & 1 & .040 & 1.746 \\
& Perception & .045 & .078 & .326 & 1 & .568 & 1.046 \\
& Practice & .090 & .052 & 3.998 & 1 & .043 & 2.094 \\
& Measures in place & .045 & .045 & 5.007 & 1 & .016 & 5.046 \\
& Constant & -3.791 & 2.262 & 2.809 & 1 & .098 & .023 \\
\hline
\end{tabular}

a. Variable(s) entered on step 1: Knowledge, Perception, Practice, Measures in place.

\subsubsection{Summary of Binary Logistic Regression Analysis}

Binary logistic regression indicates that knowledge, practice and measures in place are significant predictors of provision of PAC $[$ Chi-Square $=5.868, \mathrm{df}=4$ and $\mathrm{p}=0.001(<0.05)]$. Perception was not significant. All the 4 independent variables explain $50.3 \%$ of the variability of Provision of PAC among health care workers in Uasin Gishu County. Knowledge, Practice and Measures in place are significant at the 5\% level [Knowledge Wald $=1.710, \mathrm{p}=0.040(<0.05)$, Practice Wald $=3.998, \mathrm{p}=0.043(<0.05)$ ] and Measures in place Wald $=5.007, \mathrm{p}=0.016(<0.05)$. The odds ratio for Knowledge was $1.746(95 \% \mathrm{CI})$, for Practice was $2.094(95 \% \mathrm{CI})$ and the odds ratio for Measures put in place was $5.046(95 \% \mathrm{CI})$. The model gave an overall percentage correct prediction rate of $74.1 \%$.

\subsection{Discussion}

\subsubsection{Characteristics of the Respondents}

Study results indicated that most of the respondents $(66.7 \%)$ were registered nurses. This means that data majorly captured the experience of the nursing cadre, since they are the majority of the health workforce in the County. Dominance of female respondents was noted across all the age brackets $(80.2 \%)$. This could be explained by the higher number of female employees in the nursing profession globally and nationally, subsequently leading to a higher number of nurses being trained to provide specialized health care service across all health care fields. These findings are in concurrence with those of a similar study in Addis Ababa [4] with dominance of female respondents across all age brackets. 


\subsubsection{Knowledge on PAC among Participants}

Majority of the respondents correctly understood the two parameters of defining unsafe abortion as categorized by characteristics of either, the person conducting the procedure (being unqualified in terms of skills) and secondly, the environment where termination is being carried out (being devoid of the least health standards) or both the elements of the person and that of the environment co existing together. The respondents were more knowledgeable as compared with the findings of a similar study by [27] where only a few of the respondents were able to put the concept of unsafe abortion into perspective. The higher level of understanding in the current study could have been due to a more intense discussion of abortion following the promulgation of the new constitution in Kenya.

Less than half of the respondents understood that they are allowed by law to provide abortion related services in order to save lives. According to the legal framework, clinicians can offer PAC whenever they are appropriately trained [8]. This finding concurs with [16] that abortion laws are not clear to many health care providers. This knowledge gap could be the reason why unsafe abortion persistently remains on top has a leading killer despite all the public health efforts put in place towards its prevention.

Binary logistic regression analysis identified that knowledge on PAC among care givers is a significant variable with an odds ratio of 1.746 at $95 \%$ confidence interval.

\subsubsection{Perception on PAC among Participants}

The constitution of Kenya (article 26), stipulates that one of the circumstances that termination of pregnancy is allowed is when the wellbeing of the mother is threatened [13].

Most participants were in agreement that they will not allow PAC to a woman presenting with incomplete abortion in a pregnancy of up to 12 weeks gestation. These findings are similar with those of a study that showed that barriers to PAC uptake include poor decision making by care givers who send away deserving clients in need of service [16].

Although majority of participants confirmed that provision of PAC services was not contrary to their personal and religious beliefs, some health care workers in the County had a negative perception towards provision of PAC services, a factor that can easily contribute to preventable maternal deaths. The negative perception towards provision of PAC was further affirmed by a general lack of commitment to update their understanding on the subject of PAC so as to provide services to deserving clients. The current results also concur with those of [28] that identified barriers to PAC uptake to include poor attitude and religious objections by some providers. In the current study however, binary logistic regression results established that Perception on PAC among the care givers had a p value greater than 0.05 therefore was found not to be a significant predictor of provision of PAC at $5 \%$ level.

\subsubsection{Practices employed by the Participants in Providing PAC}

The study established that a large number of participants had not undertaken any form of training, similar to that of a medical institution in Nigeria where only one third of PAC care givers, mainly specialists reported any formal training on PAC and on more recent methods for treatment of complications brought about by unsafe abortion [29].

The poor state of training among the respondents imply that other than other greater setbacks to women receiving PAC related services, the County is faced with a deficiency of skilled trained personnel needed to execute PAC services effectively, therefore forcing women in need of services to search for it in private medical clinics, residences of traditional herbalists, places manned by untrained providers or even induce it themselves.

In line with the reproductive health guidelines, that women seeking PAC service are not necessarily required to provide evidence or proof for service [8], the study found out that awareness was lacking on this perspective among care givers. Care givers were not informed that clients who have benefitted from PAC need birth control services to assist them space births, whereas some require contraceptives services since they are not ready to conceive. These findings concur with those of [30] that established that in some cases, post-abortion family planning and contraceptive counseling is not provided due to inadequate capacity or lack of time and commitment among providers. In the current study, binary logistic regression results established that, Practice on PAC among health care workers in Uasin Gishu is a significant variable with an odds ratio of 2.094 at $95 \%$ confidence interval. When the Practice scores changes from poor to high, the odds of provision of PAC is 2.094 times higher if all other variables are kept the same.

\subsubsection{Measures put in Health Facilities for provision of PAC}

The study established that MVA Kits for provision of PAC services were inadequate in the facilities within the County. Likewise, majority of the health facilities had no space designated for PAC services. Inadequate medical supplies and absence of hospital guidelines have been mentioned in other studies [15]. Research findings further established that medical abortion drugs were frequently unavailable. This implies that availability of services including medical abortion is often hampered by stock-out of commodities in the County. This finding concurs with that of [30] that in some cases in the low resource regions, post-abortion family planning and contraceptive counseling is not provided due to missing commodities.

Binary logistic regression results established that increasing level of satisfaction among the care givers on measures put in place for management of PAC clients was significantly associated with an increased likelihood of providing PAC in Uasin Gishu. The odds of providing PAC when measures put in place are poor to the same odds when measures put in place are good, is 5.046 at $95 \%$ confidence interval. This implies that when measures put in place for provision of PAC scores change from low to high, the odds of provision of PAC is 5.046 times higher. The missing link in provision of PAC could therefore be explained by lack of commodities and supplies.

\subsection{Summary of the Study Findings}


ISSN 2250-3153

Based on study findings, three independent variables significantly influence provision of PAC in Uasin Gishu County therefore the null hypothesis of the study is rejected. Findings of this study show that PAC implementation in Uasin Gishu County was inadequate. Knowledge gap on PAC legal framework was evident among the care givers. Despite the fact that religious and personal beliefs were identified to influence perception of care givers towards provision of PAC, inferential analysis established that generally, perception on PAC was not a significant predictor for provision of PAC. Practice of PAC was poorly implemented mainly because of majority of Health workers who are yet to be trained on PAC. Medical equipment used in provision of PAC were reported as inadequate, health facilities were not adequately prepared to handle PAC clients as essential supplies was lacking. Pearson's correlation between knowledge and practices on PAC was found to be statistically significant at $\mathrm{p}<0.001$ whereas Spearmen's correlation between perception and measures put in place for provision of PAC among the respondents was also found to be statistically significant at $P<0.001$.

Binary logistic regression indicated that knowledge, practice and measures in place are significant predictors of provision of PAC among health care workers in Uasin Gishu County. [Chi-Square $=5.868, \mathrm{df}=4$ and $\mathrm{p}=0.001(<0.05)]$. Perception was not significant. The findings of this study as well as the findings of other related studies as cited in this study on provision of PAC worldwide and in developing nations identified PAC as a major strategy that needs to be implemented so as to alleviate maternal deaths brought about by unsafe abortion in Kenya and specifically in Uasin Gishu County where the study was carried out. This was consistent with most of the related studies that had been conducted elsewhere as cited in this study

\subsection{Conclusion from the study}

\section{CONCLUSION}

The conclusions of this study are based on the findings and discussions as it regards provision of PAC among Health care workers in Uasin Gishu County, Kenya. The respondents generally were aware of PAC as an intervention aimed at sorting out the problem of maternal mortality brought about by unsafe abortion.

\subsubsection{Knowledge on PAC among the Participants}

This study established that health care providers in Uasin Gishu County generally have a knowledge gap on issues relating to PAC policies as confirmed by the apparent match and contradiction of responses from health practitioners' point of view on abortion law and reproductive health policy on PAC. This knowledge gap could explain the high number of complications arising from clandestine procedures and the reason why unsafe abortion persistently remains on top has a leading killer despite all the public health efforts put in place towards its prevention. Binary logistic regression analysis further identified that knowledge on PAC among care givers was a significant predictor for provision of PAC in the County.

\subsubsection{Participant's perception towards PAC}

From this study, perception of PAC among practitioners was promising given that most of the responses matched with those recommended by reproductive health guidelines. However, despite the overall positive perception of PAC among health practitioners, negative perception was also noted among a few. Binary logistic regression results established that Perception on PAC among the care givers was found not to be a significant predictor of provision of PAC in Uasin Gishu County.

\subsubsection{Practices employed on PAC among the participants}

Based on the study findings, practice of PAC in the County was found to be poor, mainly as a result of a large number of care givers who have no formal training on PAC. The study further noted that very few participants were aware that women seeking PAC service are not necessarily required to provide proof. Lack of trained staff capable of offering PAC, impedes provision of service to women who legally qualify, subsequently leaving them with the alternative of a risky procedure and its devastating consequences of death and disability. Binary logistic regression analysis established that Practice among health care workers was found to be a significant predictor for provision of Post abortion care in Uasin Gishu County.

\subsubsection{Measures put in place for Provision of PAC in Health Facilities}

Lastly, it was deduced from the findings of this study that most designated facilities in the County were inadequately prepared to attend to women seeking PAC services as confirmed by the high number of care givers who stated that MVA Kits were not readily available for provision of PAC services. Further, most health facilities had no space designated for PAC services. Binary logistic regression established that increasing level of satisfaction among the care givers on measures put in place for management of PAC clients was the most significant predictor associated with likelihood of providing PAC in the County. This therefore implied that the low provision of PAC could mainly be as a result of missing commodities and supplies at designated health facilities. 


\section{REFERENCE}

[1]. Susheela, S., Remez, L., Sedgh, G., Kwok, L., Onda, .T. Abortion Worldwide. Uneven progress \& unequal access. New York. Guttmacher Institute, 2017

[2]. Incidence and Complications of Unsafe Abortion in Kenya. Key Findings of a National Study. Nairobi. African Population and Health Research Center, Ministry of Health, Kenya, Ipas, and Guttmacher Institute, 2013.

[3]. Rasch, V. Unsafe abortion and post abortion care: An overview. Acta Obstetricia et Gynecologica Scandinavica. Nordic Federation of Societies of Obstetrics and Gynecology, 2011.

[4]. Assefa EM. Knowledge, attitude and practice of health providers towards safe abortion provision in Addis Ababa health centers. BMC Women's Health. London. Springer Nature, 2019; 14; 19(1):138. doi: 10.1186/s12905-019-0835-x. PMID: 31727045.

[5]. Marlow HM, Wamugi S, Yegon E, Fetters T, Wanaswa L, Msipa-Ndebele S. Women's perceptions about abortion in their communities: perspectives from western Kenya. Reproductive Health Matter, 2014. 22 (43)149-58.

[6]. Hussain, R. Abortion and unintended pregnancy in Kenya. Issues Brief. New York. Guttmacher Institute, 2012.

[7]. Izugbara C, Egesa C, Kabiru C, Sidze E. Providers, Unmarried Young Women and Post-Abortion Care in Kenya. Studies in Family Planning,2017, 48(4):343-358. doi: 10.11-11/sifp.12035.

[8]. Ministry of Medical Services. Standard and Guidelines for reducing morbidity and mortality from unsafe abortion in Kenya. Nairobi: MOH, 2012.

[9]. Shah, I., Ahman, E \& Ortayli, N. Access to Safe Abortion: Progress and Challenges since the 1994 International Conference on Population and Development (ICPD), Journal of Contraception Vol. 90. doi- 10.1016/j.contraception.2014.04.004

[10]. Faundes, A., \& Miranda, L. Ethics surrounding the provision of abortion care. Best Practice \& Research Clinical Obstetrics \& Gynecology, 2017, 43, 50-57. doi:10.1016/j.bpobgyn. 2016.12.005

[11]. Paul, M., Gemzell-Danielsson, K., Kiggundu, C., Namugenyi, R., \& Klingberg-Allvin, M. Barriers and facilitators in the provision of post-abortion care at district level in central Uganda-a qualitative study focusing on task sharing between physicians and midwives. BMC Health Services Research, 2014, 14(1), 1. doi:10.1186/1472-6963-14-28.

[12]. Chiweshe, M., \& Macleod, C. If you choose to abort, you have acted as an instrument of Satan'. Zimbabwean health service providers' negative constructions of women presenting for post abortion care. International Journal of Behavioral Medicine, 2017, 24(6)856-863. Doi:10.1007/s12529-017-9694-8

[13]. Government of Kenya. The Constitution of Kenya, 2010 revised edition. Nairobi; National Council for Law Reporting (NCLR), 2010.

[14]. Campbell OM, Aquino EM, Vwalik B, Gabrysc S. Signal functions for measuring the ability of health facilities to provide abortion services: an illustrative analysis using a health facility census in Zambia. 2016, BMC Pregnancy Childbirth 16: 105.

[15]. Sully, E. A., Madziyire, M. G., Riley, T., Moore, A. M., Crowell, M., Nyandoro, M. T., Madzima, B., \& Chipato, T. Abortion in Zimbabwe: A national study of the incidence of induced abortion, unintended pregnancy and post-abortion care in 2016. 2018, Plos One, 13(10), e0205239. doi:10.1371/journal.pone.0205239

[16]. Bacon, A., Ellis, C., Rostoker, J., \& Olaro, A. Exploring the role of midwives in Uganda's Post abortion Care: Current practice, barriers, and solutions. International Journal of Childbirth, 2014, 4(1), 4-16. doi:10.1891/2156-5287.4.1.4

[17]. Trueman, K. \& Magwentshu M. Abortion in a Progressive Legal Environment: The Need for Vigilance in Protecting and Promoting Access to Safe Abortion Services in South Africa, American Journal of Public Health, 2013, vol. 103, No. 3.

[18]. Geary CW, Gebreselassie H, Awah P \& Pearson E. Attitudes toward abortion in Zambia. International Journal of Gynecology and Obstetrics, 2012, 118(2) 148-151.

[19]. Harries, J., Cooper, D., Strebel, A., \& Colvin, C. J. Conscientious objection and its impact on abortion service provision in South Africa: A qualitative study. Journal of Reproductive health, 2014, 11(1), 16.

[20]. Mutua M, Manderson L, Musenge E, Achia T. Policy, law and post-abortion care services in Kenya. PLoS ONE, 2018, 13(9).

[21]. Drabo, S. Access to Post Abortion Care in Burkina Faso: an ethnographic study. University of Oslo, Faculty of Medicine, Institute of General Practice and Community Medicine. Section for International Health, 2013.

[22]. Paluku, J. Kalisoke, S, Wandabwa, J. \& Kiondo, P. Knowledge and attitudes about induced abortions among female youths attending Naguru Teenage Information and Health Centre, Kampala, Uganda. Journal of public health and epidemiology, 2013, 5(4) 178-185.

[23]. Kenya National Bureau of statistics. Kenya Population and Housing Census. Nairobi. Government Printers, 2009.

[24]. Nassiuma, D. K. Survey sampling theory and methods. Nairobi: University of Nairobi Press, 2000.

[25]. Tavakol, M \& Dennick, R. Making sense of Cronbach's alpha," International Journal of Medicine. Education, 2011. Vol. 2, pp. 53-55.

This publication is licensed under Creative Commons Attribution CC BY.

http://dx.doi.org/10.29322/IJSRP.11.09.2021.p11703

www.ijsrp.org 
[26]. Mugenda OM \& Mugenda AG. Research methods, Nairobi, Kenya, ACTS press, 2003.

[27]. Tesfaye, G., \& Oljira, L. Post abortion care quality status in health facilities of Guraghe zone, Ethiopia. Reproductive Health, 2013, 10(35), 1-7. Doi:10.1186/1742-4755-10-35.

[28]. Hakansson, M., Oguttu, M., Gemzell-Danielsson, K., \& Makenzius, M. Human

rights versus societal norms: A mixed methods study among healthcare providers on social stigma related to adolescent abortion and contraceptive use in Kisumu, Kenya. BMJ Global Health, 2018, 3(2), e000608. doi:10.1136/bmjgh-2017-000608

[29]. Kalu, C. A., Umeora, O. U. J., \& Sunday-Adeoye, I. Experiences with provision of post-abortion care in a university teaching hospital in South-East Nigeria: A five year review. African Journal of Reproductive Health, 2012, 16(1), 105-112.

[30]. Tagoe-Darko, E. "Fear, shame and embarrassment": The stigma factor in post abortion care at Komfo Anokye Teaching Hospital, Kumasi, Ghana. Asian Social Science,2013, 9(10), 134. doi:10.5539/ass.v9n10p134. 